\title{
Viver e Não Ter a Vergonha de Ser Feliz: Música e Produção de Sentidos num CAPS da Amazônia Ocidental
}

Vivir y no Tener la Vergüenza de Ser Feliz: Música y Producción de Sentidos en un CAPS de la Amazonía Occidental

To Live and not be Ashamed of Being Happy: Music and Production of Senses in a CAPS in Western Amazon

Eraldo Carlos Batista

ORCID: http://orcid.org/0000-0002-7118-5888 Fundação Universidade Federal de Rondônia, Rondônia/Brasil

Dayane Fernandes Ferreira

ORCID: http://orcid.org/0000-0002-9237-774X Fundação Universidade Federal de Rondônia, Rondônia/Brasil

Luana Karoline da Silva Batista

ORCID: http://orcid.org/0000-0002-1663-5399 Faculdade de Rolim de Moura, Rondônia/Brasil

Edvania Wessling

ORCID: http://orcid.org/0000-0001-7803-8031 Faculdade de Rolim de Moura, Rondônia/Brasil

\section{Resumo}

O objetivo com este estudo foi descrever a importância da música no auxílio à reabilitação social de usuários de um Centro de Atenção Psicossocial (CAPS I) da região Amazônica. Trata-se de uma pesquisa qualitativa realizada por meio de uma entrevista semiestruturada com dez participantes de uma oficina de música. A análise dos depoimentos foi realizada com base na Análise do Discurso, sob a perspectiva da Psicologia Discursiva, e permitiu identificar quatro repertórios interpretativos: a) a música como recurso ativador das lembranças; b) a oficina de música como elemento de desconstrução social do preconceito; c) os encontros musicais como espaço de interação social; e d) as atividades musicais como recurso terapêutico. Conclui-se que a intervenção por meio da música pode refletir na instituição da saúde de forma positiva, proporcionando a instauração de um ambiente terapêutico no qual o usuário se sente valorizado em dimensões que normalmente não são abordadas no sistema convencional de assistência à saúde.

Palavras-chave: Música; Reabilitação social; Interação social.

\section{Resumem}

El objetivo con este estudio fue describir la importancia de la música en el auxilio a la rehabilitación social de usuarios de un Centro de Atención Psicosocial (CAPS I), de la región Amazónica. Tratase de una investigación cualitativa, realizada por medio de una entrevista semiestructurada con diez participantes de un taller de música. El análisis de los testimonios tuvo como orientación el Análisis del Discurso, bajo la perspectiva de la Psicología Discursiva, y permitió identificar cuatro repertorios interpretativos: a) la música como recurso activador de las recordaciones; b) el taller de música como elemento de desconstrucción social del prejuicio; c) los encuentros musicales como espacio de 
interacción social; y d) las actividades musicales como recurso terapéutico. Concluyese que la intervención por medio de la música puede reflejar en la institución de salud de manera positiva, proporcionando la instauración de un ambiente terapéutico en el cual el usuario se siente valorado en dimensiones que normalmente no son abordadas en el sistema convencional de asistencia a la salud.

Palabras clave: Música; Rehabilitación social; Interacción social.

\begin{abstract}
The objective with this study was to describe the importance of music in assisting social rehabilitation of users of a Psychosocial Care Center (CAPS I) in the Amazon region. This is a qualitative research performed through a semi structured interview with ten participants of a music workshop. The analysis of statements had as guide the Discourse Analysis, under the perspective of Discursive Psychology, and helped to identify four interpretative repertoires: a) music as a memory activator resource; b) music workshop as an element of social deconstruction of prejudice; c) music workshop as a space of social interaction; d) musical activities as therapeutic resource. It was concluded that the intervention through music can reflect positively in the health institution, by providing the establishment of a therapeutic environment, in which the user feels valued in dimensions that are not recurrent in the conventional system of assistance to health.
\end{abstract}

Keywords: Music; Social rehabilitation; Social interaction.

\section{Introdução}

A música, por ser inerente à própria constituição do homem, havendo registros de sua presença em todos os tempos e culturas, possui uma íntima relação com vários aspectos da atividade humana. Como linguagem universal, a música tem sido utilizada e ampliada de acordo com cada época da história da humanidade.

Por exercer influências psicológicas quase infinitamente variadas sobre o comportamento do indivíduo, a música como abordagem terapêutica é utilizada desde a Antiguidade, configurando-se um recurso para promoção, prevenção e tratamento de doenças somáticas e mentais (Bergold \& Alvim, 2009). Platão utilizava a música para o tratamento das angústias fóbicas vivenciadas naquela época, e Aristóteles apontava os benefícios da música no cuidado da tristeza, melancolia e emoções incontroláveis (Matoso \& Oliveira, 2017).

Como arte que valoriza a autoexpressão, a música pode ser utilizada com o intuito de despertar nos ouvintes emoções das mais diversas, dependendo do momento vivido (Zanettini et al., 2015), proporcionando sentimentos de moral, alegria, melancolia, devoção, violência, sensualidade, calma, entre outros. De acordo com Zimmermann (2007), o homem pré-histórico já expressava suas emoções por meio de uma linguagem musical, mesmo que ainda muito rude e primitiva, por meio de gestos, gritos e da dança, no intuito de atrair a proteção divina e afastar os maus espíritos, as doenças e até a morte.

Na perspectiva da atenção psicossocial, as atividades musicais, como apontam Batista e Ribeiro (2016), devem estar articuladas com melhoria da qualidade de vida, criação e fortalecimento de desejos, afetos, prazeres e vínculos tanto no interior dos serviços quanto no território em que os usuários desses serviços transitam. Nesse sentido, os autores supracitados acrescentam que as atividades musicais podem se tornar um potencial instrumento de intervenção de baixo custo, não farmacológica e não invasiva, no desenvolvimento de intervenções terapêuticas que visam à promoção, reabilitação e inclusão da pessoa em sofrimento mental.

Como prática na humanização do cuidado, a música pode exercer a função de 
elemento facilitador na interação do profissional de saúde com o paciente em sofrimento mental, fazendo com que o relacionamento entre os atores envolvidos se torne mais harmonioso e produtivo. Nesse sentido, os serviços de atenção psicossocial precisam dispor de operadores de diversas categorias profissionais, muitas consideradas externas à área de saúde (Amarante, 2011), como, por exemplo, os músicos.

As atividades musicais podem ser realizadas em diversos contextos, como oficinas, dinâmicas, apresentações; com grupos distintos: grupos de usuários, de profissionais de saúde mental, com a família ou com todos juntos, com o intuito de propiciar a aproximação entre todos os atores envolvidos no processo de reinserção social da pessoa em sofrimento mental. Sob essa ótica, compreende-se que a utilização da música é de grande importância na atenção psicossocial na medida em que a sua utilização pode ocorrer de maneiras multivariadas.

\section{Música, saúde mental e investigação científica}

Pesquisas vêm sendo realizadas considerando vários aspectos da utilização da música como instrumento de intervenção terapêutica no campo da saúde. Esses estudos confirmam que a investigação científica dos aspectos e processos psicológicos ligados à música é tão antiga quanto as origens da psicologia como ciência (Bréscia, 2003). Dessa maneira, as atividades musicais se mostram um importante instrumento para a saúde coletiva por serem capazes de auxiliar no processo de saúde-doença, e podem ter objetivos profiláticos nos aspectos físico, psíquico e mental, além disso contribuem para a redução dos índices de ansiedade, depressão, estresse e dor, melhoram o condicionamento físico e os padrões cardiorrespiratórios, bem como potencializam o desenvolvimento humano (Gainza, 2014; Matoso \& Oliveira, 2017).

Da mesma forma, Chiarelli e Barreto (2005) afirmam que nos hospitais a música tem sido utilizada antes, durante e após os procedimentos cirúrgicos com o objetivo, entre outros, de baixar a ansiedade e melhorar o estado emocional do paciente e até diminuir os sintomas de pacientes que fazem tratamento quimioterápico. Nessa mesma direção, Oliveira, Lopes, Damasceno e Silva (2012) discutem a atuação da música no tratamento de doenças neurológicas como Alzheimer, Parkinson, entre outras. De acordo com esses autores, ouvir música afeta a liberação de substâncias químicas cerebrais poderosas que podem regular o humor, reduzir a agressividade e a depressão e melhorar o sono.

A música também é apontada como um elemento positivo na elevação da autoestima do indivíduo e na sua forma de se relacionar com o outro. Em pesquisa Batista e Ribeiro (2016) concluíram que o desenvolvimento de atividades musicais como recurso terapêutico na atenção psicossocial pode gerar impactos positivos aos usuários, como bem-estar, recordações e melhora das relações sociais, além de colaborar na constituição de vínculos e no desenvolvimento de mudanças pessoais e coletivas. Corroborando esses achados, o estudo realizado por Batista e Ferreira (2015) com usuários de um Centro de Atenção Psicossocial (CAPS) do interior de Rondônia revelou que as atividades musicais contribuíram para a desconstrução de preconceitos e estigmas internalizados social e culturalmente ao longo do tempo pelos usuários. Da mesma forma, Coqueiro, Vieira e Costa (2010), ao aplicarem arteterapia em um CAPS de Fortaleza, concluíram que a adesão e o envolvimento dos sujeitos implicados no processo propiciaram mudanças nos campos afetivo, interpessoal e relacional.

Mesmo com a existência de uma vasta literatura nacional com foco na utilização da música como instrumento de intervenção terapêutica na atenção psicossocial, ainda se verifica uma escassez de investigações sobre a temática na região Amazônica. Ou seja, constatou-se uma importante lacuna na literatura, que aponta a necessidade de pesquisas nessa região para que possam ser evidenciados os benefícios da música no 
processo de reabilitação psicossocial da pessoa em sofrimento mental.

Desse modo, neste estudo teve-se como indagação a seguinte questão norteadora: quais os sentidos produzidos acerca dos benefícios das atividades musicais desenvolvidas num CAPS pelos seus usuários? Para responder a tal pergunta, objetivou-se investigar sobre a importância da música no auxílio à reabilitação social de usuários de um CAPS da região Amazônica.

\section{Método \\ Delineamento}

Este estudo foi realizado por meio de uma pesquisa descritiva de abordagem qualitativa orientada pela Psicologia Discursiva (Potter \& Wheterell, 1987), que se alinha aos pressupostos do construcionismo social (Gergen \& Gergen, 2010). Na Psicologia Discursiva o discurso psicológico do senso comum é transformado em práticas de discursos e estudado sem nenhuma referência específica da psicologia acadêmica, pois se compreende que os conceitos que as pessoas usam em suas vidas cotidianas têm suas próprias maneiras de funcionar, simplesmente porque são os meios reais e empiricamente disponíveis por meio dos quais elas explicam a si mesmas (Edwards, 2004).

Destarte, a Psicologia Discursiva focaliza seu interesse na atenção à construção do conhecimento no discurso e na explicação de como se produz tal conhecimento, como se constrói a interpretação da realidade, e como as interações entre analistas e participantes criam e adquirem sentido (Iñiguez, 2004). Os processos de produção de sentido na Psicologia Discursiva são compreendidos como construções sociais, coletivas e interativas, por meio dos quais as pessoas inseridas em um determinado contexto sóciohistórico-cultural criam os termos a fim de compreenderem e atribuírem significado aos fenômenos (Spink \& Medrado, 2004), os quais tem a linguagem como base. Em síntese, a Psicologia Discursiva é entendida como o estudo de como as pessoas constroem, montam e ocultam relatos que descrevem e invocam estados e características psicológicas (Edwards, 2004).

\section{Participantes}

Participaram do estudo 10 usuários de um CAPS I situado na região Amazônica, sendo três do sexo masculino e sete do sexo feminino (ver Tabela 1), participantes de uma oficina de atividades musicais. As oficinas aconteciam semanalmente e eram realizadas por um psicólogo e um músico voluntário. Os encontros tinham duração de duas horas e eram planejados com os participantes. Foram listados como critérios de inclusão na pesquisa: 1) estar em tratamento no CAPS pesquisado; 2) ter participado da oficina de música; 3) apresentar nível de consciência e orientação preservada e nível satisfatório de verbalização.

\section{Local da pesquisa}

Quanto ao local da pesquisa, trata-se de um CAPS I localizado em um munícipio do interior do Estado de Rondônia com aproximadamente 60.000 habitantes. Contudo, o atendimento no referido CAPS é regionalizado, atendendo outros sete municípios vizinhos. Compõem a equipe de profissionais duas psicólogas, um psiquiatra, um enfermeiro, dois farmacêuticos, um técnico de enfermagem, dois técnicos administrativos e uma auxiliar de serviços gerais. No que se refere à estrutura física, o CAPS possui salas individuais para atendimentos psicológicos, psiquiátricos, recepção, atividades em grupo, para arquivo de documentos, uma cozinha, dois banheiros, um almoxarifado e uma área grande utilizada pelos usuários para aguardar atendimento.

\section{Coleta e análise das informações}

Após a aprovação da pesquisa os participantes foram contatados para apresentação dos objetivos do estudo e o convite de participação. As entrevistas foram realizadas em uma sala da Instituição, de acordo com a disponibilidade de cada 
participante nos dias de realização da oficina, após a leitura e a assinatura do Termo de Consentimento Livre e Esclarecido (TCLE), e tiveram duração média de 35 minutos, sendo gravadas em áudio e transcritas na íntegra.

Para a constituição e a análise do corpus da pesquisa, foram realizadas entrevistas abertas sobre os sentidos produzidos pelos usuários a respeito de sua participação nas atividades musicais desenvolvidas no CAPS, realizadas entre junho e dezembro de 2015. Como método de análise do material empírico, utilizou-se a Análise do Discurso.

Existem várias definições de Análise do Discurso, e cada uma delas satisfaz as próprias preocupações dos distintos autores e enfatiza aspectos diferentes. Em linhas gerais, Análise do Discurso refere-se ao estudo das práticas linguísticas para esclarecer as relações sociais estimuladas e mantidas pelo discurso (Iñiguez, 2004). Neste estudo o caminho teórico-metodológico escolhido para analisar o corpus se baseia na proposta de Análise do Discurso sob a orientação da Psicologia Discursiva (Potter \& Wheterell, 1987). A Análise do Discurso nessa perspectiva enfatiza o processo dialógico e performático da linguagem, considerando o conteúdo do discurso como disponível socialmente e utilizado conforme os objetivos específicos da conversação (Rasera \& Rocha, 2010). De acordo com essa proposta teóricometodológica, toda linguagem, mesmo a aparentemente descritiva, é sempre construtiva e constitui uma ação (Potter \& Wetherell, 1987).

A partir dessa proposta, a análise propriamente dita se iniciou com a transcrição das entrevistas, observando e anotando os aspectos relevantes para a atividade interpretativa, como entonações e inflexões de voz (Guanaes, 2006). Os passos seguintes foram a leitura flutuante e atenta das transcrições das entrevistas, a seleção do tópico grupal e a identificação dos repertórios interpretativos.

\section{Aspectos éticos}

Esta pesquisa foi aprovada pelo Comitê de Ética da Faculdade de Rolim de Moura (FAROL), sob o número 770.715 e CAAE de número 33585414.7.0000.5605. Ressalta-se que todos os procedimentos éticos foram respeitados, e os nomes dos participantes foram substituídos por códigos de acordo com a ordem das entrevistas.

\section{Resultados e discussão Caracterização dos participantes}

As atividades musicais realizadas no CAPS pesquisado envolvem usuários de perfis heterogêneos, sendo pessoas de diferentes idades, gêneros, hipóteses diagnósticas, graus de instrução e localidades de residência. Considerando que a Psicologia Discursiva está interessada nas práticas discursivas das pessoas e em sua organização em diferentes tipos de contextos (Rasera, 2013), torna-se relevante apresentar algumas características dos participantes deste estudo.

A análise descritiva dos dados demográficos (Tabela 1) indicou que a maioria dos participantes é do sexo feminino, com faixa etária predominantemente compreendida entre 32 e 41 anos, divorciados seguidos de solteiros e com hipótese diagnóstica de transtornos depressivos ou esquizofrenia.

Tabela 1

Análise descritiva dos dados demográficos

\begin{tabular}{ccccccc}
\hline Usuário & Sexo & Idade & Estado civil & Escolaridade & Ocupação & Hipótese diagnóstica \\
\hline E1 & F & 32 anos & Divorciada & Oitavo ano & Do lar & Depressão \\
E2 & F & 38 anos & Divorciada & Séries iniciais & Desempregada & Depressão \\
E3 & M & 26 anos & Solteiro & Ensino médio & Desempregado & Esquizofrenia \\
E4 & F & 29 anos & Casada & Sexto ano & Do lar & Esquizofrenia \\
E5 & M & 41 anos & Casado & Séries iniciais & Pensionista & Esquizofrenia \\
\hline
\end{tabular}
(Continua) 
Tabela 1

Análise descritiva dos dados demográficos (continuação)

\begin{tabular}{ccccccc}
\hline Usuário & Sexo & Idade & Estado civil & Escolaridade & Ocupação & Hipótese diagnóstica \\
\hline E6 & M & 49 anos & Divorciado & Analfabeto & Pensionista & Depressão \\
E7 & F & 34 anos & Solteira & Oitavo ano & Do lar & TOC \\
E8 & F & 35 anos & Casada & Ensino médio & Desempregada & Ansiedade \\
E9 & F & 39 anos & Divorciada & Sexto ano & Do lar & Depressão \\
E10 & F & 58 anos & Divorciada & Analfabeta & Pensionista & Depressão \\
\hline
\end{tabular}

A presença marcante do sexo feminino neste estudo pode ser explicada pelas diferenças de gênero no acesso aos serviços de saúde e autocuidado, construídas histórica, cultural e socialmente e reproduzidas pelos programas e políticas de saúde que ainda privilegiam cuidados estereotipados para cada um dos sexos (Botton, Cúnico, \& Strey, 2017).

Ao analisar a faixa etária predominante e sua relação com a ocupação dos entrevistados, observa-se que estes vivem em momentos de baixa produtividade laborativa. Tal condição pode ser explicada também pelo baixo nível de instrução dos usuários, considerando que a maioria não concluiu o ensino fundamental, o que sugere que a manifestação do adoecimento mental parece contribuir para o abandono escolar (Freitas, Matos, Silva, Santos, \& Batista, 2017).

\section{Repertórios interpretativos}

Com o objetivo de conhecer os sentidos produzidos acerca das atividades musicais presentes nas entrevistas, buscou-se identificar e analisar os repertórios interpretativos que melhor representavam a importância da música no auxílio à reabilitação social de cada entrevistado. Como repertórios interpretativos, compreendem-se os dispositivos linguísticos que os sujeitos utilizam para construir versões das ações, eventos e outros fenômenos que estão à sua volta. Eles são marcados por termos, metáforas, sinais, figuras de linguagem e imagens utilizados na conversação, compartilhados e disponíveis como um recurso social, utilizados para justificar alguma versão particular de um evento, para validar ou questionar os próprios comportamentos e para manter sua credibilidade na interação (Potter \& Wheterell, 1987).

Desse modo, a identificação dos repertórios utilizados pelos falantes favorece a possibilidade de categorização, dando maior visibilidade ao processo de produção de sentido (Rasera \& Rocha, 2010). Partindo da análise dos trechos de conversas que abordavam os sentidos produzidos sobre a participação na oficina de música pelos usuários, agruparam-se repertórios interpretativos em torno de quatro temas, a saber: a) a música como recurso ativador das lembranças; b) a oficina de música como elemento de desconstrução social do preconceito; c) os encontros musicais como espaço de interação social; e d) as atividades musicais como recurso terapêutico.

Cabe salientar que os nomes próprios dos entrevistados foram substituídos por códigos, como mostrado na Tabela 1 , onde a letra "E" designa o entrevistado, e o número, a ordem em que foram realizadas as entrevistas.

\section{A música como recurso ativador das lembranças}

Em diferentes entrevistas, foi possível observar, por meio do discurso dos participantes, que cada música provocava reações emocionais distintas, desencadeando momentos de euforia ou mesmo de intensa melancolia entre os usuários. Os sentidos produzidos nessas falas relacionam-se às lembranças associadas à letra ou à melodia de determinada música que remetem a momentos vividos de grandes significados para esses entrevistados.

Os participantes referem-se às atividades musicais como um momento de 
reencontro com o passado e de reflexão sobre a própria vida. Os trechos a seguir foram extraídos do momento em que se perguntou como eles descreviam os encontros no grupo de atividades musicais.

Muita emoção, é muito gostoso, é maravilhoso! É... A oficina, ela te traz boas lembranças. Faz você lembrar das coisas [situações da vida] ruins que passaram, mas também de coisas boas. Às vezes a gente chora com uma determinada música [silêncio]. Eu estava chorando, mas não era de tristeza, mas, sim, de emoção, de alegria. Então pra mim isso foi muito gratificante, me comoveu bastante, mexeu bastante comigo. (E5, 39 anos).

Essas músicas me fazem voltar ao passado [silêncio]. Eu lembro da minha juventude, lembro da minha adolescência na casa dos meus pais [emocionado]. É como se passasse um filme na minha cabeça, mas depois me sinto aliviado. É bom esse exercício. (E10, 58 anos).

[...] não sei explicar bem, mas parece que tudo fica mais alegre. Parece que volto no tempo. (E9, 39 anos).

A música pra mim é como um filme, sabe? Ela me remete às lembranças das coisas boas vividas. Dos namoros [risos], das festas, dos bailes. Eita, que coisa boa! [risos]. Às vezes quando estão cantando uma música do meu tempo eu fecho os olhos parece que estou ali naquela época vivendo tudo de novo [silêncio]. (E6, 49 anos).

Essas falas evidenciam a satisfação dos usuários em participar do grupo, indicando que as atividades realizadas com música são gratificantes e proporcionam melhor vinculação ao tratamento. Resultados semelhantes a estes foram encontrados no estudo de Batista e Ribeiro (2016), os quais concluíram que a utilização da música no contexto terapêutico, além de promover a expressão de emoções e a percepção da realidade, favorece o equilíbrio interno e facilita espaços para relacionamentos. E essas trocas simbólicas podem ser observadas na sensibilidade dos usuários ao perceberem mudanças de sentimentos ocorridas no outro durante os encontros musicais, como se observou a partir das falas a seguir:
É muito bom ver as pessoas que estavam ali em torno, o olhar delas a cada música. Porque você sente a... Você olhando no olhar das pessoas, você sente a expressão de alegria; porque lá fora, se você está sentado lá [na recepção], você só escuta falar de problemas, e aqui não, só se vê alegria. (E5, 39 anos).

E é contagiante! Parece que todos que estão aqui estão mais felizes. Isso é muito gratificante. (E10, 58 anos).

Eu gosto muito porque a gente fica mais próximo uns dos outros, né. Eu não estava me sentindo muito bem, mas daí ela [usuária] foi até onde eu estava e me convidou pra cantar com ela, e eu me senti bem melhor. (E9, 39 anos).

Eu já fiz muitas amizades aqui. Tem pessoas que lá fora [recepção] a gente nunca conversava e agora somos amigos. Eu acho que a música faz isso: [silêncio] aproximar as pessoas. Aqui nos tornamos uma família. (E5, 41 anos).

Por meio dessas afirmativas, verificase que esses usuários não são apenas sensíveis às suas necessidades e especificidades dentro do grupo de atividades musicais, mas que se apropriaram dos encontros para estabelecer novas relações sociais. Considerando-se a importância das relações estabelecidas entre os entrevistados, atribui-se à música um papel de intermediadora e facilitadora das trocas sociais 
nesses encontros, $\mathrm{o}$ que facilita $\mathrm{o}$ estabelecimento de novos vínculos (Batista \& Ribeiro, 2016), por meio da conscientização de si e do outro dentro da perspectiva do coletivo, sendo avaliada como um recurso positivo no processo de reabilitação e inserção social da pessoa em sofrimento psíquico.

É muito bom. Aqui a gente esquece os problemas da vida, a gente canta, a gente dança, se abraça, é maravilhoso. Nos dias que tem música aqui no CAPS eu vou embora mais leve, sabe? A gente até trata as pessoas melhor [risos]. (E9, 39 anos).

Pra mim, esse momento é... [silêncio] É como se eu não tivesse nenhum problema na cabeça [risos]. Se tivesse música todos os dias, todos os dias eu vinha no CAPS [risos]. Às vezes eu chego aqui meio desanimado, sabe? Meio triste, meio pra baixo, mas depois que começo a cantar, isso tudo desaparece, é só alegria [risos]. (E6, 49 anos).

Nessas falas, observam-se os efeitos da música a partir da percepção dos entrevistados sobre os seus estados emocionais antes e após o início das atividades em grupo, sobre a mudança do próprio status de tristeza para alegria e o despertar das emoções. Nas palavras de Wazlawick, Camargo e Maheirie (2007), ao vivenciar a música o sujeito ultrapassa as barreiras da matéria musical em si, isto é, altura, duração, intensidade, timbre, estrutura e expressão, e suas relações, passando a perceber toda uma rede de significados construídos no seu mundo social e histórico, seja nos contextos coletivos mais amplos, seja nos contextos singulares.

Assim, os entrevistados expõem em seus depoimentos um posicionamento discursivo que reafirma as atividades artísticas e musicais, entre outras, como práticas circunscritas no bojo das ações em saúde mental a partir da reabilitação psicossocial e das propostas reformistas. Ou seja, a realização dessas atividades representa um recurso significativo na ressocialização e inserção do usuário em grupos, na medida em que propõe o pensar coletivo, conferido por uma lógica inerente ao paradigma psicossocial, respeitando a diversidade, a subjetividade e a capacidade de cada sujeito (Azevedo \& Miranda, 2011).

\section{A oficina de música como elemento de desconstrução social do preconceito}

Outro repertório presente nas entrevistas foi "a música como alternativa na desconstrução social do preconceito". Trata-se de um repertório utilizado para expressar os sentimentos negativos dos usuários quanto aos estigmas sofridos diante do sofrimento mental. Os fragmentos a seguir foram retirados do momento em que os participantes respondiam à indagação: na sua opinião o que mudou na sua relação com o sofrimento mental após sua participação na oficina de atividades musicais?

Esse repertório traz como principal elemento discursivo os estigmas vividos pelos entrevistados relacionados ao preconceito. Nas primeiras falas fica evidente que os próprios usuários tendem a reproduzir uma construção social negativa dos serviços de saúde mental.

$E u$, antes de vir passar no CAPS, achava que quem passava por psiquiatra era louco. Tinha um preconceito, sabe? Daí eu precisei. Estava com dificuldade $e$ me encaminharam para cá. Só que quando comecei o tratamento vi que não era isso. E participando da oficina vi que outras pessoas têm problemas, como eu tinha, e que não é o fim, mas que tem como a gente resolver, sabe? (E3, 26 anos).

Antes de participar desse grupo eu ficava incomodado ali na frente. Porque eu não gostava de vir aqui, sempre ouvia as pessoas dizendo que aqui é lugar de gente doida [risos]. Agora eu não vejo chegar o dia que o rapaz vem tocar e cantar com nós. É 
muito bom. (E4, 29 anos).

Percebeu-se nas entrevistas que o preconceito acerca do adoecimento mental ainda é um fator existente e persistente. De acordo com Xavier, Klut, Neto, Ponte e Melo (2013), isso se deve ao fato de que a pessoa acometida por algum transtorno psíquico ainda é percebida socialmente como um indivíduo perigoso, imprevisível, responsável pela sua doença, preguiçoso ou vítima digna de pena. Essa visão, segundo os autores, é pouco crítica e provinda de noções fortalecidas, muitas vezes, pelos meios de comunicação social, que contribuem para a manutenção desses estereótipos.

Quem está no CAPS, assim, as outras pessoas de fora acham que... Tomar remédio controlado, a gente é uma pessoa, assim, descontrolada, uma pessoa fora do normal [silêncio]. $O$ mesmo que dizer que a pessoa está ficando louca porque está passando por psiquiatra [silêncio]. Passou por psiquiatra, então, é "doido". Eu fiquei aliviada hoje da menina ter falado aquilo dali [sobre o preconceito de quem vai ao CAPS]. Então fiquei mais aliviada. (E10, 58 anos).

As pessoas daqui não tem preconceito uns com os outros, isso me faz sentir bem melhor. Aqui no grupo me sinto gente de verdade [risos]. (E2, 38 anos).

Eu tinha preconceito e até vergonha de mim mesmo. Não falava que vinha aqui [no CAPS]. Mas participando da oficina eu me senti muito bem! Porque quem está aqui [usuários do CAPS] sabe como é a gente tomar remédio tarja preta e como é visto pelas pessoas. (E6, 49 anos).

Como exposto, as atividades em grupo desempenham um importante papel na desconstrução do preconceito, da angústia, dos medos e dos estigmas inerentes ao sofrimento psíquico, construídos e reforçados pelo viés histórico, social e cultural pela sociedade, ao oportunizarem momentos para discussão e reflexão sobre o tema entre os usuários (Batista \& Ferreira, 2015). Além disso, a troca de experiências entre os participantes oportuniza o desenvolvimento de um senso mais crítico e com novos olhares sobre o sofrimento mental, levando essas pessoas a produzir concepções diferentes acerca do seu processo de adoecimento.

\section{Os encontros musicais como espaço de interação social}

Esse repertório sobre as atividades musicais está relacionado ao coletivo e às interações sociais. A socialização que emerge nos encontros é considerada pelos usuários uma forma de produzir novas amizades, descobertas, trocas de experiências e diversão. Pelos relatos pode-se perceber que são vários os meios que a música possibilita a esses usuários para romper com o isolamento físico e social. Isso pode ser visualizado nos trechos a seguir:

Eu me senti dez [...] porque a gente estava em bastante gente na sala, cada um contou um pedacinho da sua vida, cantou música. $E$ isso que distrai bastante a gente. Lá fora [na recepção] a gente espera, espera, espera e espera, mas, sabe, depois que vim pra cá [sala de grupos] foi ótimo demais [risos]. Se tivesse mais vezes na semana seria melhor [risos]. (E7, 34 anos).

Eu gosto mesmo quando canta todo mundo junto. Fica mais animado, né? Também gosto porque aqui fiz novos amigos. Quando a gente sai daqui [do grupo] a gente fica um bom tempo conversando. $\dot{E}$ muito bom isso. (E6, 49 anos).

Isso é maravilhoso. Eu me dou bem com todo mundo, aqui sou amigo de todos. Eu acho que se essa oficina continuar [risos] acho que sai até 
casamento aqui [risos]. (E6, 49 anos).

Esse repertório mostra que os usuários atribuem significados à música a partir de suas vivências e experiências nas atividades musicais, avaliadas por estes como positivas. Os sentidos produzidos pelos entrevistados sobre essas atividades refletem os aspectos transformadores dos seus cotidianos, marcados por imagens e palavras relacionadas à troca, socialização, convívio, coletividade, interação e corresponsabilidade. Para Batista e Ferreira (2015), os encontros realizados por meio das oficinas de entretenimento propiciam diálogo, compartilhamento de histórias de vida e reconhecimento coletivo e individual dos participantes, o que possibilita a compreensão das diferenças, das experiências, além de melhorar a capacidade de criar e multiplicar os saberes de cada um.

A música também foi percebida pelos usuários como elemento fundamental para $\mathrm{o}$ atendimento humanizado e o estabelecimento de vínculos entre usuários e profissionais, como mostram as falas a seguir:

Eu achei maravilhosa essa oficina... Amo a música. E gostei desde o começo até o fim. Gostei demais achei tudo muito bom. Porque isso aqui humaniza o atendimento, o relacionamento das pessoas, os relacionamentos interpessoais. Então eu achei maravilhoso, adorei. (E10, 58 anos).

Eu acredito que esses encontros humanizam mais a gente. É o que eu penso. A gente ficava muito isolado, só conversava quando era atendido pelo médico. Aqui não; a gente conversa com todo mundo. Me sinto gente novamente [risos]. (E1, 32 anos).

Como mencionado pelos entrevistados, a música pode ser um importante instrumento na promoção de intervenções mais humanizadas em saúde. A música, aplicada como terapia em saúde, conforme Fonseca et al. (2009), possibilita uma assistência diferenciada ao paciente, que passa a ser entendido como sujeito ativo dentro do processo saúde-doença, proporcionando a recomposição do ser humano como um ser integral.

Aqui no grupo a gente fica mais à vontade pra falar de nossas vidas. E o que é legal é que as pessoas daqui uns tentam ajudar os outros. Isso dá força pra gente. A gente vê que não está sozinho, e que outras pessoas estão passando pelos mesmos problemas. (E3, 26 anos).

Aqui [no grupo] eu não tenho vergonha de falar da minha doença. Pelo contrário, aqui as pessoas comentam os seus problemas como coisas comuns das suas vidas. Eu acho que as letras das músicas ajudam muito, sabe? Elas encorajam a gente falar. (E5, 41 anos).

Diante dessas falas, compreende-se que a música é descrita também como recurso para transformações individuais e grupais no enfrentamento de situações difíceis do cotidiano dos entrevistados. Nesse sentido, Coqueiro et al. (2010) afirmam que a música proporciona uma grande mudança no modo de pensar da pessoa em sofrimento psíquico. De acordo com os autores, ela propicia mudanças nos campos afetivo, interpessoal e relacional, melhorando o equilíbrio emocional, fazendo com que diminua o isolamento e aumente o diálogo entre os próprios usuários, ou seja, além da utilização como instrumento na reabilitação da saúde mental do usuário, a música exerce um papel fundamental de inclusão desse sujeito.

\section{As atividades musicais como recurso terapêutico}

Esse repertório está relacionado ao processo de produção de sentidos sobre os efeitos terapêuticos da música no processo de reabilitação social. Nas atividades musicais 
realizadas no referido CAPS, utilizavam-se estratégias multivariadas, como canto, dança, execução de instrumentos musicais, roda de conversas e trocas de experiências. Assim, os encontros se tornaram um espaço de discussão e desconstrução de valores, exercendo uma função mediadora do sujeito consigo próprio e deste com os outros. Foi possível verificar a satisfação dos usuários participantes deste estudo ao descreverem os sentidos produzidos sobre os benefícios da música tanto ao corpo quanto à mente.

As falas a seguir surgiram dos momentos em que os entrevistados foram indagados sobre como se sentiam após participarem das atividades musicais.

A oficina é importante para nós pacientes. A gente sabe que a música causa bons sentimentos nas pessoas, então faz com que a gente se sente melhor quando sai daqui. (E8, 35 anos).

Ah! A música me dá tranquilidade, paz, eu sinto assim [silêncio] parece que me dá esperança [silêncio]. Parece que os problemas vão ser mais fáceis de serem resolvidos, parece que eu tenho mais força pra enfrentar a doença, porque pra mim sempre será uma doença. É essa esperança que me dá mais força pra lutar. (E2, 38 anos).

Observa-se que as atividades musicais utilizadas como método de ação nos encontros se revelaram um subsídio para a expressão da subjetividade do sujeito e para a expressão de seus sentimentos. Conforme as falas dos sujeitos entrevistados, os benefícios da música exercem uma preciosa alternativa terapêutica para o grupo, capaz de modificar atitudes e comportamentos, estados de ânimo e, sobretudo, as relações interpessoais; possibilita o desenvolvimento da autonomia e socialização, na medida em que o envolvimento do participante lhe permite se reconhecer na terapia (Backes, Ddine, Oliveira, \& Backes, 2003; Resende et al.,
2015).

Muita coisa boa, filha! Não tem nem... Nem tem como explicar, porque isso vai ficar aqui [apontando para cabeça], vou ficar lembrando desses momentos maravilhosos que vivi aqui. Vou lembrar que antes eu só pensava em coisas tristes e participando do grupo eu passei a pensar só em coisas que me dão alegria. Estou me sentindo como uma jovem de 20 anos [risos]. (E10, 58 anos).

Eu gosto muito de prestar atenção nas letras das músicas e refletir sobre elas, sabe? Então, eu vejo que a música me ajuda a enfrentar os meus problemas [silêncio]. Tenho certeza disso. (E6, 49 anos).

Diante do exposto, compreende-se que a utilização da música no referido CAPS proporciona um ambiente terapêutico, no qual os sentimentos são compartilhados e as questões relativas ao estado emocional dos sujeitos ganham novos contornos no enfrentamento, refletindo na sua saúde de forma positiva. Esses benefícios ocorrem, entre outros fatores, em razão de os usuários se sentirem valorizados em dimensões que normalmente não são abordadas no sistema convencional de assistência à saúde (Fonseca et al., 2009).

Desse modo, a música, por ser uma intervenção terapêutica de baixo custo, não medicamentosa e não invasiva, é vista como uma ótima opção de recurso na área da saúde, pois agrega uma maior importância, em decorrência da necessidade de se trabalhar com gastos menores e alcance do maior eco terapêutico possível (Resende et al., 2015).

Então, eu me senti bem em estar junto com as pessoas que entendem o que a gente passa. Hoje eu lido muito bem com isso, na verdade esses encontros me ajudaram a me ver diferente [risos]. (E6, 49 anos). 
Olha eu era mais estressada antes de participar do grupo. Eu vivia de mau humor, e parece que depois que eu comecei a vir aqui eu mudei meu jeito de ser [risos]. Acho que estou melhor. (E1, 32 anos).

Eu acho que a oficina me ajudou na comunicação. Eu não gostava de conversar. Na verdade, nem de ver gente [risos]. Aqui aos poucos fui ficando mais desinibida. Agora converso com todos do grupo. Já até cantei uma música sozinha [risos]. (E4, 29 anos).

Nesse repertório interpretativo, as atividades musicais são descritas como ações interventoras nas mudanças dos estados emocionais dos entrevistados. As falas anteriormente expostas revelam outras formas de lidar com os aspectos emocionais desenvolvidos pelos usuários a partir do envolvimento nas atividades. Nesse sentido, a utilização da música no processo terapêutico, aplicada de forma sistemática, constitui-se uma forma inovadora que, além de contribuir na humanização dos cuidados em saúde mental, poderá ajudar o usuário a expressar seus sentimentos e emoções, fazendo emergir aspectos saudáveis e fomentando a comunicação (Resende et al., 2015).

Eu era bem mais ansiosa, sabe? Eu vinha pra cá [para o CAPS] e ficava pensando nas coisas que eu tinha que fazer em minha casa, ficava irritada com a demora do atendimento do médico. Agora eu tenho percebido que mesmo quando não tem música eu me sinto mais tranquila. (E2, 38 anos).

Nos dias que tem música aqui no CAPS eu saio daqui mais calmo, menos ansioso, menos estressado [risos]. Mais relaxado [risos]. (E6, 49 anos).

Essas falas corroboram estudos que comprovam os benefícios da música na vida das pessoas, como melhora do humor, do sono, da motivação, da autoconfiança, diminuição da ansiedade, auxílio no combate à tensão e na eliminação do estresse (Zanettini et al., 2015).

Por outro lado, Cedraz e Dimenstein (2005) ressaltam que não é a simples existência de uma oficina que garante a produção de novas formas de vida. Para os autores, a fim de que a música seja terapêutica é necessário se conectar com uma dimensão distinta da que habitualmente se encontra o ser humano e que leva necessariamente a uma reflexão acerca das conexões existentes entre produção desejante e produção da vida material.

\section{Considerações finais}

Neste estudo objetivou-se descrever os sentidos produzidos acerca das experiências vividas por usuários de um CAPS I situado na região Amazônica que participaram de uma oficina de entretenimento com atividades musicais. Em linhas gerais os resultados mostraram que a oficina desenvolvida com os usuários do CAPS investigado teve papel significativo para amenizar os efeitos negativos do sofrimento mental, promover bem-estar e mudanças nos campos afetivo, emocional, interpessoal e relacional de cada participante.

Foi possível identificar por meio do discurso dos participantes que a grande maioria dos entrevistados reconhece a importância da oficina de música no enfrentamento da doença mental. Ou seja, os encontros proporcionaram a esses usuários não somente um momento de entretenimento, mas também momentos de reflexão e reconhecimento de si mesmos enquanto sujeitos da sua própria história. Os sentidos produzidos sobre a participação na oficina refletem a inclusão desses usuários em um grupo social, porém não uma inclusão no sentido restrito de estar inserido em um grupo, mas, sobretudo, de participação ativa, como de escolha do repertório, de liberdade de expressão de sentimentos, de respeito à 
diversidade, à subjetividade e à singularidade de cada sujeito.

Aspectos importantes relacionados aos efeitos da música como aliada ao enfrentamento do sofrimento mental foram produzidos pelos participantes. Pode-se constatar que a música teve papel como ativadora das lembranças, possibilitando aos entrevistados um reencontro consigo mesmos e um retorno aos momentos que marcaram suas vidas. Promoveu a ressignificação de lembranças e a percepção da realidade, gerando novas formas de expressão das as emoções. A cada encontro novos elementos surgiam nas trocas de experiências de vida de cada sujeito.

Também ficou evidente que os debates realizados nos encontros musicais durante as oficinas produziram sentidos relacionados ao estigma sofrido pela pessoa em sofrimento mental. Provocaram a autorreflexão sobre o adoecimento e a necessidade de mudança de paradigmas relacionados à doença mental.

Em suma, os sentidos produzidos pelos usuários em relação às oficinas de música no referido CAPS mostram que os encontros foram capazes de proporcionar a eles sensações de conforto, alegria, paz, tranquilidade, além de possibilitarem novos laços de amizade e companheirismo. Os efeitos positivos foram relatados pelos próprios participantes, como melhoria na comunicação, menos estresse e ansiedade.

No entanto, ressalva-se que com este estudo a pretensão não era esgotar e nem contemplar todos os benefícios da música no enfrentamento da doença mental. Assim, apontam-se lacunas que devem ser superadas por meio de novas investigações. Dentre as limitações destaca-se o número reduzido de participantes na oficina, considerando o universo atendido pelo CAPS investigado; outro fator a ser considerado é a não contemplação dos usuários na utilização dos instrumentos musicais. Seria interessante, também, pensar a oficina de música como espaço de aprendizagem, o que aumentaria o leque de oportunidades de participação e envolvimento dos usuários.

Este trabalho pode favorecer outras reflexões acerca dos sentidos que foram produzidos. Assim, sugere-se que novas pesquisas sejam realizadas com populações maiores e oficinas diversificadas nos CAPS dessa região, a fim de que se amplie o debate sobre a discrepância dos investimentos em ações de políticas públicas voltadas à saúde no País, sobretudo à saúde mental.

\section{Referências}

Amarante, P. (2011). Saúde mental e atenção psicossocial. 3. ed. Rio de Janeiro: Fiocruz. Azevedo, D. D., \& Miranda, F. A. N. D. (2011). Oficinas terapêuticas como instrumento de reabilitação psicossocial: percepção de familiares. Esc Anna Nery, 15(2), 339-345.

Backes, D. S., Ddine, S. C., Oliveira, C. D. L., \& Backes, M. T. S. (2003). Música: terapia complementar no processo de humanização de uma CTI. Nursing, 6(66), 37-42.

Batista, E. C., \& Ferreira, D. F. (2015). A música como instrumento de reinserção social na saúde mental: um relato de experiência. Revista Psicologia em Foco, 7(9), 67-79.
Batista, N. S., \& Ribeiro, M. C. (2016). O uso da música como recurso terapêutico em saúde mental. Revista de Terapia Ocupacional da Universidade de São Paulo, 27(3), 336-341.

Botton, A., Cúnico, S. D., \& Strey, M. N. (2017). Diferenças de gênero no acesso aos serviços de saúde: problematizações necessárias. Mudanças-Psicologia da Saúde, 25(1), 67-72.

Bergold, L. B., \& Alvim, N. A. T. (2009). A música terapêutica como uma tecnologia aplicada ao cuidado e ao ensino de enfermagem. Escola Anna Nery Revista de Enfermagem, 13(3), 537-542. 
Bréscia, V. L. P. (2003). Educação musical: bases psicológicas e ação preventiva. São Paulo: Átomo.

Cedraz, A., \& Dimenstein, M. (2005). Oficinas terapêuticas no cenário da Reforma Psiquiátrica: modalidades desinstitucionalizantes ou não? Revista Mal Estar e Subjetividade, 5(2), 300-327.

Chiarelli, L. K. M., \& Barreto, S. D. (2005). A música como meio de desenvolver a inteligência e a integração do ser. Revista Recre@rte, (3), 1699-1834.

Coqueiro, N. F., Vieira, F. R. R., \& Costa, M. M. (2010). Arteterapia como dispositivo terapêutico em saúde mental. Acta Paulista de Enfermagem, 23(6), 859-862.

Edwards, D. (2004). Psicologia Discursiva: unindo teoria e método como exemplo. In L. Iñiguez (Ed.). Manual de análise do discurso em ciências sociais. (pp. 181-205). Petrópolis, RJ: Vozes.

Fonseca, K. C., Barbosa, M. A., Silva, D. G., Fonseca, K. V., Siqueira, K. M., \& Souza, M. A. (2009). Credibilidade e efeitos da música como modalidade terapêutica em saúde. Revista Eletrônica de Enfermagem, $8(3)$.

Freitas, B. S., Matos, C. C. R., Silva, P. M., Santos, J. S., \& Batista, E. C. (2017). Perfil de usuários diagnosticados com esquizofrenia de um CAPS do interior de Rondônia. Nucleus, 14(1), 41-54.

Gainza, V. H. (2014). Estudos de Psicopedagogia Musical. 3. ed. São Paulo: Summus.

Gergen, K. J., \& Gergen, M. (2010). Construcionismo social: um convite ao diálogo. Rio de Janeiro: Instituto NOOS.

Guanaes, C. (2006). A construção da mudança em terapia de grupo: um enfoque construcionista social. São Paulo: Vetor.

Iñiguez, L. (2004). A Análise do Discurso nas ciências sociais: variedades, tradições e práticas. In L. Iñiguez (Ed), Manual de Análise do Discurso em Ciências Sociais (pp. 105-160). Petrópolis, RJ: Vozes.

Matoso, L. M. L., \& de Oliveira, A. M. B. (2017). O efeito da música na saúde humana: base e evidências científicas.
Ciência \& Desenvolvimento Revista Eletrônica da FAINOR, 10(2), 76-98.

Oliveira, G. C., Lopes, V. R. S., Damasceno, M. J. C. F., \& da Silva, E. M. (2012). A contribuição da musicoterapia na saúde do idoso. Revista Cadernos UniFOA, 20, 8594.

Potter, J., \& Wetherell, M. (1987). Discourse and social psychology. London: Sage Publications.

Rasera, E. F. (2013). A Psicologia Discursiva nos estudos em Psicologia Social e Saúde. Estudos e Pesquisas em Psicologia, 13(3), 815-834.

Rasera, E. F. \& Rocha, R. M. G. (2010). Sentidos sobre a prática grupal no contexto de saúde pública. Psicologia em Estudo, 5(2), 35-44.

Resende, R. L., Souza, L., Lucchese, R., Vera, I., Castro, P. A., \& Mónico, L. (2015). A vivência de pessoas em sofrimento mental e alunos de enfermagem em oficina de música. CIAIQ2015, 1(1), 421-425.

Spink, M. J., \& Medrado, B. (2004). Produção de sentidos no cotidiano: uma abordagem teórico- metodológico para análise das práticas discursivas. In M. J. Spink (Ed.), Práticas discursivas e produções de sentido no cotidiano: aproximações teóricas e metodológicas (pp. 17-39). Rio de Janeiro: Cortez.

Xavier, S., Klut, C., Neto, A., Ponte, G. D., \& Melo, J. (2013). O estigma da doença mental: que caminho percorremos? Psilogos: Revista do Serviço de Psiquiatria do Hospital Fernando Fonseca, 11, 10-21.

Wazlawick, P., Camargo, D. D., \& Maheirie, K. (2007). Significados e sentidos da música: uma breve "composição" a partir da psicologia histórico-cultural. Psicologia em Estudo, 12(1), 105-113.

Zanettini, A., Souza, J. B. D., Eloá, V., Finger, D., Gomes, A., \& Santos, M. S. D. (2015). Quem canta seus males espanta: um relato de experiência sobre o uso da música como ferramenta de atuação na promoção da saúde da criança. Revista Mineira de Enfermagem, 19(4), 1060-1069.

Zimmermann, N. (2007). A música através dos tempos. São Paulo: Paulinas. 


\section{Dados sobre os autores:}

- Eraldo Carlos Batista: Doutorando em Psicologia pela Pontifícia Universidade Católica PUCRS, Mestre em Psicologia pela Fundação Universidade Federal de Rondônia - UNIR, Especialista em Saúde Mental pela Universidade Católica Dom Bosco - UCDB, Professor Substituto pela UNIR.

- Dayane Fernandes Ferreira: Mestranda em Educação pela Fundação Universidade Federal de Rondônia - UNIR, bolsista da Coordenação de Aperfeiçoamento de Pessoal de Nível Superior (CAPES).

- Luana Karoline da Silva Batista: Graduanda em Direito pela Faculdade de Rondônia - FAROL.

- Edvania Wessling: Graduada em Psicologia pela Faculdade de Rolim de Moura - FAROL. 